Stina Bengtsson*, Karin Fast, André Jansson and Johan Lindell

\title{
Media and basic desires: An approach to measuring the mediatization of daily human life
}

https://doi.org/10.1515/commun-2019-0122

\begin{abstract}
The extended reliance on media can be seen as one indicator of mediatization. But even though we can assume that the pervasive character of digital media essentially changes the way people experience everyday life, we cannot take these experiences for granted. There has recently been a formulation of three tasks for mediatization research; historicity, specificity and measurability, needed to empirically verify mediatization processes across time and space. In this article, we present a tool designed to handle these tasks, by measuring the extent to which people experience that media reach into the deeper layers of daily human life. The tool was tested in an empirical study conducted in Sweden in 2017. The results show that perceived media reliance is played out in relation to three types of basic desires: (1) (re)productive desires, (2) recognition desires, and (3) civic desires, and is socially structured and structuring. We argue this tool, in diachronic analyses, can measure one important aspect of mediatization.
\end{abstract}

Keywords: mediatization, media reliance, daily life, basic desires, social stratification

\section{Introduction}

As most daily practices become (trans)mediated and a growing range of objects turn into carriers of information (ultimately creating the 'internet of things') there are fewer and fewer areas of our lives left untouched by media. Along with the

\footnotetext{
*Corresponding author: Stina Bengtsson, Media and Communication Studies, Södertörn University, Huddinge, Sweden, E-Mail: stina.bengtsson@sh.se.

Karin Fast, Media and Communication Studies. Karlstad University, Karlstad, Sweden, E-Mail: karin.fast@kau.se.

André Jansson, Media and Communication Studies. Karlstad University, Karlstad, Sweden, E-Mail: andre.jansson@kau.se.

Johan Lindell, Department of Informatics and Media, Uppsala University, Uppsala, Sweden, E-Mail: johan.lindell@im.uu.se.
} 
shift from electronic mass media to digital transmedia systems we have seen the interdependences between media technology and daily human life expand beyond those communication processes that "media" used to refer to. This extended reliance, ultimately indispensability, of media can be seen as a key indicator of mediatization, whereby our lives become dependent on, and adapted to, media (Jansson, 2014, 2018). According to some researchers, the pervasiveness of digitalization and datafication has extended this meta-process of social change into a stage of "deep mediatization" (Andersen, 2018; Couldry and Hepp, 2016; Hepp, 2016), defined as "the increased reliance of all social processes on infrastructures of communication" (Couldry and Hepp, 2016, p. 37, italics in original). But how are we to validate whether these general observations of digital media saturation resonate with people's lived experience? To what extent do different groups experience that different areas of their lives are reliant on media? And is there any way to empirically verify change?

There seems to be consensus around the idea of mediatization as a process of change, a temporal expansion; yet few studies have approached mediatization empirically from such a perspective. While qualitative studies have provided rich and varied pictures of how media saturate specific parts of everyday life, they neither suffice to substantiate claims regarding change, that is, growing media reliance (for an example of a panel study, though, see Peil and Röser, 2014), nor provide an overview of which dimensions of daily life such changes affect. Furthermore, qualitative studies cannot empirically validate variations within a broader population and thus fail to grasp which underlying factors condition experiences of growing media reliance. In order to shed light on mediatization as a process of change operating across different social realms, qualitative studies can be complemented by quantitative, longitudinal studies of media reliance that may help us explore both the 'deepening' and the 'expansion' of mediatization over time. In this article, we introduce a research instrument that we have developed for such studies and implemented in a survey study in 2017. We thus seek to provide a contemporary view of perceived media reliance as well as a 'point zero' for longitudinal research.

Our endeavor responds to recent calls among mediatization scholars. Three empirical challenges for mediatization research, needed to theoretically advance the field, have been singled out: historicity, specificity, and measurability (Ekström et al., 2016). Historicity points to the temporal dimension of mediatization theory and the urge to study mediatization across time, that is, as a process. Specificity deals with the variation between media technologies, genres, and institutions, and how they may shape mediatization processes differently in different contexts and in relation to different groups. Measuring mediatization, lastly, means that "the degree to which various actors and individuals adapt their practices and 
mindsets to media and mediation processes is quantified and thus directly comparable across time and space" (ibid., p. 1102, italics in original). In response to these challenges, the present study is an attempt to make a specific aspect of mediatization measurable and as such comparable in time and space. Mediatization as a “complex meta-process” (Krotz, 2007) covering macro- as well as micro-processes in society and culture is, of course, not measurable as a whole. Still, in order to validate the 'deeper' dimensions of mediatization over time, we have constructed a set of survey questions that aims at measuring the experience of media reliance in relation to the basic desires that make up daily human life. As such, we try to break down the complex meta-process into empirically graspable units. While our study does not deal with media specificity (for reasons presented in the subsequent section), it gets at a specific aspect of mediatization (perceived media reliance) and its articulation within specific dimensions of daily life (basic desires). The historicity of mediatization will here be approached using a time series, of which this study serves as the starting point. This obviously means that earlier phases of mediatization will not be covered by this study, but it will provide a point of departure for future time series that will help verifying historical change.

Following the notion of deep mediatization, our research instrument is thus designed to go beyond the commonplace understanding of media as important merely for communicative purposes to explore mediatization as the perceived reliance on media for the basic dimensions of daily human life. Our understanding of these deeper layers of daily human life is informed by social psychological research, specifically Stephen Reiss' (2004) renowned empirical work on sixteen basic human desires (which will be developed further on). In sum, the research instrument presented in this article enables us to diachronically (to verify change) explore the degrees to which people experience that basic elements of their daily lives are reliant on media (depth) and in which domains (expansion). It also enables us to compare these developments demographically and between countries and regions (another form of expansion), thus opening up a view of mediatization as a socially differentiated process (Ekström et al., 2016). Diachronic and comparative studies are crucial for exploring divergent expressions and variations of mediatization across historical epochs as well as cultures.

With this approach we aim at exploring the following three research questions:

1. To what degree do people perceive that they rely on media to fulfill the sixteen basic desires that (according to Reiss' theory) make up daily human life?

2. How is perceived media reliance structured along different dimensions of daily human life?

3. How is perceived media reliance in daily human life influenced by demographic factors? 
We argue that this analytical approach, which we intend to test and further elaborate through longitudinal studies, holds the potential to complement and develop existing mediatization research and validate (or counter) some of the basic claims of mediatization theory. The results presented in this article constitute a starting point in this endeavor.

\section{Why and how to measure mediatization?}

While the strongest proponents of mediatization have advanced the idea of mediatization as a "new paradigm" for media studies (Hepp, Hjarvard, and Lundby, 2015; also Lunt and Livingstone, 2016), there are also sceptical voices claiming that mediatization has so far been too vaguely defined and ultimately runs the risk of turning into a concept that "has no outside" (Deacon and Stanyer, 2015, p. 657). One obvious problem is that the escalating use of the term implies that there are multiple, sometimes contradictory, interpretations of what mediatization means. This does not suggest, however, that we should refrain from further analyses of mediatization. On the contrary, it calls for further theoretical elaboration and empirical scrutiny that can validate the defining criteria of mediatization.

In our view, there are three such criteria, around which there also seems to be much intellectual consensus (see, e. g., Couldry and Hepp, 2013; Hjarvard, 2013; Krotz, 2014, 2017; Lundby, 2014). First, mediatization refers to a process of historical change. Mediatization is not a fixed state but reflects the growing importance of media in society. Second, mediatization refers to the ways in which various forms of human activity are adapted to, or become reliant on, media, ultimately making media technologies indispensable to daily human life. This is to say that mediatization deals with the deeper significance of media rather than with particular media effects. Third, mediatization refers to structural change rather than single instances of media adaptation or alterations within the lifeworlds of individuals. We must therefore make sure to relate particular cases of mediatization to broader contexts (Krotz, 2017, p. 108), and empirically compare mediatization processes across social fields, demographic groups, institutions, geo-social environments, etc.

Measuring mediatization is one way to empirically explore, and possibly verify, these three criteria. It does not mean that we want to reduce mediatization to "a lot of causal relationships or statistical values" (Krotz, 2017, p. 113). Nor do we claim to capture all aspects of the complex meta-process of mediatization with our study. However, developing appropriate quantitative meas- 
ures for longitudinal studies of how and in what areas of people's daily life media reliance grows, would help us substantiate the underlying assumptions related to mediatization, including what Couldry and Hepp (2016) call "deep mediatization". The latter means that media become "crucial to the elements and processes out of which the social world and its everyday reality is formed and sustained" (p. 213, italics in original). In much mediatization research (as well as in media research more broadly), this assumption - which is ultimately an assumption about social change - has been treated as a point of departure for case studies rather than an area of empirical inquiry in itself (Ekström et al., $2 ß 16)$. There is empirical evidence, based on numerous studies conducted over the last two decades or so, that media have become increasingly influential as a molding force in contemporary societies as well as in the fundamental dimensions of daily life and human existence. But there are currently no longitudinal measurements that can substantiate whether and how this process is evolving, that is, potentially deepening and expanding into a growing number of areas of human life and different social environments. This study is a humble step in that direction.

Quantitative analyses of mediatization can be found primarily within the fields of journalism and political communication (e.g., Strömbäck, 2011; Strömbäck and Dimitrova, 2011), but these are (for obvious reasons) confined to a particular institutional setting, dealing especially with the adaptation of mainstream politics to the logics of news media. There are a few interesting examples of survey research pertaining to the mediatization of social life, particularly how people experience media dependence (Hjarvard, 2019), but these have not yet included any attempts to develop more general indicators that, in future endeavors, can be used in longitudinal studies.

What we want to add to existing research is thus a way of measuring mediatization based on how people's perceived media reliance in the basic dimensions of human life develops over time. In this article, we present a research instrument and a study that will be the starting point for a statistical time series regarding the mediatization of daily human life, which may also open up for comparisons across demographic categories and between different countries. Others have identified the relevance of such analyses before us. Ball-Rokeach (1985), for example, calls for perspectives that consider individual media dependencies (the micro level) in relation to the wider societal context (the macro level), including media systems as well as political, economic, and social systems (see also Couldry and Hepp, 2016).

The development of this kind of instrument involves two main challenges. First, it is not possible to "measure mediatization" at large, as a "complex meta-process" (Krotz, 2007). What we can achieve, however, are valid meas- 
urements pertaining to certain sub-processes and aspects of mediatization and certain dimensions of media reliance (see, e. g., Krotz, 2014; Schulz, 2004). In this study, our key concern is to identify the extent to which mediatization plays into the basic dimensions of daily human life (an approach we elaborate below) in all segments of the population. We also confine our analysis to perceived media reliance (in contrast to, e. g., statements of media use or access), in order to make the findings compatible with qualitative studies of human experiences of mediatization. This means that reliance is analyzed from an "emic" point of view, that is, based on the respondents' subjective estimations of how important media technology is to satisfying various desires in their lives (Harris, 1976). In this approach, we follow Couldry's and Hepp's notion of “deep mediatization” (2016) as we aim to grasp the mediatization of daily human life more broadly, beyond the mediatization of mere communicative processes. This broad but inherently micro-oriented approach to mediatization is connected to the macro-structures of society through its demographic analysis.

The second challenge concerns media specificity. Different media operate in different ways, meaning that their roles in mediatization processes vary. However, given our ambition to establish an instrument for longitudinal comparisons we cannot take such variations into account. The impact of particular technologies and platforms is notoriously volatile and does not say much about the overall force of mediatization. Rather, what we do assess is the extent to which media in general - implicitly taken as media repertoires (e. g., Hasebrink and Popp, 2006; Schrøder, 2015) - are considered important, even indispensable, to different dimensions of daily human life. One could thus say that our approach to mediatization is socially oriented rather than media-centric (cf. Couldry, 2012; Couldry and Hepp, 2016; Knoblauch, 2013; Morley, 2009). In choosing this approach, we align with Ball-Rokeach's (1985) argument that "before we can fully understand channel- or media-specific dependencies, we must first understand the role of the media system in society and in individuals' lives" (p. 488). This implies that we side-step one of the basic sets of claims of current mediatization theory: that mediatization develops in different phases, depends on different kinds of media, and that the current phase of digitization and datafication mediatizes culture and society in its own way. This does not mean, however, that we dismiss such claims and assumptions, only that the longitudinal perspective urges we adopt a more general way of thinking about media.

While this can be seen as a shortcoming of this study, we hope our generalized media concept will engender a broader understanding of the changing role of media in daily human life. While our current study lacks the temporal dimension that will make it a proper measurement of media-related social change, we believe that future replications of the study (which are planned within this 
project) can validate the research instrument. In such future studies, the research instrument will also be combined with additional, more time-bound, survey questions in order to capture, for instance, how perceived media reliance is related to specific media repertoires. We return to these issues in the Method section.

\section{Understanding the "fundamentally human": Basic dimensions of daily human life}

In order to operationalize experiences of mediatization and assess their depth in relation to different dimensions of daily human life, we first need to approach the question of which fundamental elements make up human life. There is no ultimate 'truth' in this regard but different theoretical models to choose from. One possible way would be to turn to philosophy and its various approaches to "the meaning of life" such as Aristotle's 12 end motives (Barnes, Thompson, and Tredennick, 1976) or Descartes' six “passions of the soul” (1637/1958, see also Reiss, 2004, p. 184). Such dimensions, however, are philosophically constructed, and we cannot know in what ways they actually form people's daily lives.

Another well-known approach to this question is that of basic human needs; attempts to detect what it means, and what it takes, to be human. The father of this theory is Abraham Maslow (1943), whose basic-need-theory is widely known in popular discourse but also criticized for being too biologistic and for lacking empirical evidence. Looking closer at Maslow's theory, his focus was in fact not human needs but human motivation - goals in relation to which people act in daily life. Social psychologists in this tradition have kept looking at motivation, understood as variable internal states that, when activated or aroused, energize and direct how people act (Pittman and Ziegler, 2007, p. 474). While basic needs are conceptualized as biological (and thus general), motivations are social and individual (Pittman and Ziegler, 2007, p. 483). Furthermore, human motivation theory builds upon the Aristotelian distinction between means and ends, which in social psychology has been conceptualized as extrinsic versus intrinsic motivation (Deci and Ryan, 1985). Intrinsic motivation refers to things we do because they are inherently interesting or enjoyable (ends), whereas extrinsic motivation refers to things we do because they lead to a separable outcome (means) (Ryan and Deci, 2000, p. 55).

We have, in our attempt to study mediatization, constructed our research instrument based on Steven Reiss's theory of sixteen basic human desires that empirically verify what motivates the daily activities of individuals (Reiss, 2004; Reiss and Havercamp, 1998). We have chosen this model because of the empirical rigor with which it has been developed and the many studies that have applied 
it in different socio-cultural settings. As such, it gives us the opportunity to link mediatization research to a well-established empirical tradition.

A basic desire is: (a) an end goal, and thus an intrinsic form of motivation, which (b) contains universal motivators, and (c) is of psychological importance. Basic desires are thus thought to be of universal relevance, although their importance varies between individuals, social groups, and cultures (Reiss, 2004, p. 185). ${ }^{1}$ Based on empirical work, Reiss has classified basic desires into a unitary, globally valid scheme of intrinsic motivation that can be applied across different populations (Reiss, 2004, p. 180). ${ }^{2}$

Reiss concludes that there are sixteen empirically constructed basic desires that produce specific feelings of joy in daily life (different for all desires; see Table 1) but which are prioritized differently by different individuals (Reiss, 2004, p. 186), and which also relate to culturally constructed norms. Theoretically, each basic desire is regarded a continuum of potential motivation.

Table 1: Reiss' list of sixteen basic desires (after Reiss, 2004).

\begin{tabular}{ll}
\hline Motive & Intrinsic feeling \\
\hline Power (desire to influence, leadership, related to mastery) & Efficacy \\
Curiosity (desire for knowledge) & Wonder \\
Independence (desire to be autonomous) & Freedom \\
Status (desire for social standing, including attention) & Self-importance \\
Social contact (desire for peer companionship, including play) & Fun \\
Vengeance (desire to get even, compete, and win) & Vindication \\
Honor (desire to obey a traditional moral code) & Loyalty \\
Idealism (desire to improve society, altruism, justice) & Compassion \\
Physical exercise (desire to exercise muscles) & Vitality \\
Romance (desire for sex, including courting) & Lust \\
Family (desire to raise own children) & Love \\
Order (desire to organize, including ritual) & Stability \\
\hline
\end{tabular}

1 Reiss works in the "independent list" tradition (Pittman and Ziegler, 2007, p. 481), which grounds its understanding of human motivation in a set of basic categories with no internal hierarchy. Any hierarchy among the categories should instead be understood as socially and individually anchored and varies as such between groups and cultures (p. 483).

2 An initial list of 500 items was later reduced to 328, a list that research participants were asked to rate in relation to how important each of the basic desires was in determining their behavior. The empirical material consisted of three exploratory studies and one confirmatory study with a combined total of 2,554 American individuals within an age range from 12 to 76 years and from various life stages. The factor analyses of these studies supported an initial solution of fifteen basic desires, which was later complemented with a sixteenth desire, confirmed by further complementary empirical studies (Reiss, 2004; Reiss and Havercamp, 1998). 


\begin{tabular}{ll}
\hline Motive & Intrinsic feeling \\
\hline Eating (desire to eat) & Satiation \\
Acceptance (desire for approval) & Self-confidence \\
Tranquility (desire to avoid anxiety, fear) & Safety, relaxation \\
Saving (desire to collect, value of frugality) & Ownership \\
\hline
\end{tabular}

Basic desires are closely connected with values, which explains the historically close connection between motivation studies and virtue ethics (as in Aristotle's Nicomachean Ethics, 330 BCE/1953). According to this, the empirically derived list of basic desires and universal human values should have similarities. This connection is confirmed by a large study comparing 97 survey studies on values in 44 countries (Schwarz, 1994), which identified ten values of universal character, all of which correspond with one of the sixteen basic desires identified in Reiss' list (Reiss, 2004, p. 186). ${ }^{3}$ The strong empirical underpinning of Reiss' list speaks to its validity as a vantage point for generating grounded understandings of how daily human life is organized in different contexts. Reiss' theory has been used in communication research before, in studies of participation in online communities (Bishop, 2007) and in social computing applications (Vassileva, 2012), and of why users disclose information in social media (Krasnova, Spiekermann, Koroleva, and Hildebrand, 2010), to mention but a few studies. We, on the contrary, use it as vantage point to empirically nail down the most fundamental dimensions of daily human life, which we will use to measure degrees of perceived media reliance. This also emphasizes that our study does not follow the uses and gratifications tradition (Katz, Blumler, and Gurevitch, 1973), as it neither analyzes the uses nor the gratifications of media in everyday life. Instead we aim to explore in which dimensions of daily human life a statistically representative sample of the population (here Swedes) perceives the deepest reliance on media (in a broader sense).

3 Reiss' theory of 16 basic desires has been criticized for lacking a theoretical basis for determining the exact number of motives there in fact are, whether motives are independent or related, and which particular adapted modules of the human brain mediate them as well as lacking an element of evolutionary theory which would allow us to better nail down the exact number of fundamental dimensions (Bernard, Mills, Swenson, and Walsch, 2005). Such evolutionary and social psychological aspects are of minor importance as we use Reiss' theory only to map out the basic dimensions of daily human life. 


\section{Method}

We used Reiss' sixteen empirically grounded basic desires as a vantage point for our construction of a research instrument that measures perceived media reliance in the most fundamental dimensions of daily human life. Used in a time series which is the underlying goal of our project ${ }^{4}$ - this instrument holds the potential of also measuring the mediatization of daily human life. We used a survey that asked a representative sample of the Swedish population (16 to 85 years old) to estimate the importance of media in different areas of daily life, developed from Reiss' sixteen basic desires. Based on factor analysis we could then extract three dimensions of daily human life. The survey, which was administered and put in the field online by research institute Kantar-Sifo on February 9 and closed on March 1, 2017, comprises answers to questions on media, lifestyles and demographic background variables. By March 1, 3,850 individual answers had been collected setting the answering frequency at $24 \%$. The data was weighted to compensate for a relatively low answering frequency among individuals aged 16 to 29 years.

Since we seek to develop an instrument that can be used also in future analyses, we cannot ask about specific media, as they are likely to change; hence the key question was formulated as follows (translated from Swedish): "There are many different media in our everyday lives, for example, newspapers, radio, television, computers, and mobile phones. How important do you find media for you to [dimension of daily human life 1-16]?” The answers could range from 1, "media not important at all" to 7, "media very important". This methodological approach means that the notion of media in the questions is very abstract. We have used examples of different kinds of media (radio, television, computers, and mobile phones) in order to make the question more comprehensible. For the same reason we have transformed the very abstract notions of the 16 basic desires (power, acceptance, etc.) into concrete formulations such as "How important do you find media for you to influence others? Or “...get recognition from others?”

To return to the earlier theoretical discussion about mediatization we need to also critically discuss what our instrument can in fact measure. We have already mentioned that we do not measure how perceived media reliance correlates with the use of different kinds of media technologies. This is a shortcoming of our study that future replications must correct. More complicated to handle is the fact that what we grasp with this method is only the articulations of mediati-

4 This project, 'Measuring Mediatization', was funded by the Anne-Marie and Gustaf Ander Foundation for Media Research. 
zation that the respondents are aware of and able to reflect upon, and not the implicit roles of media in daily human life. The deep-mediatization thesis also builds on the assumption that media have penetrated deeply into the mundane dimensions of human life, even beyond what is graspable with the human eye (Couldry and Hepp, 2016; see also Deuze, 2014). If this is correct, survey research does not suffice to explore (deep) mediatization. Such dimensions are then only graspable either through an analysis of the technological development per se (cf. Andersen, 2018) or through long-term ethnographic explorations of people's practices. If we still want to grasp how it feels to live through a phase of mediatization and to do this over time, we argue we need to ask how people experience their lives with the media (their perceptions). Here we explore this approach to complement other approaches to the study of mediatization. As such, we collect a type of information that has thus far been absent from mediatization research and which, in combination with other empirical findings, will contribute to a broadened research agenda and more sustainable theoretical claims.

In order to control for the risk that we in fact only measured the significance of the sixteen basic desires themselves and not the importance of media in relation to them, we included questions about the basic desires per se, without adding a media component, to see if and in which ways the answers to the two kinds of questions correlated. We found that our main variables of concern - those that ask about the importance of media in relation to the sixteen basic desires - only to a low degree correlated (Pearson's $R$ between 0.1 and 0.5 ) with the corresponding sixteen variables capturing the general importance of these desires (Reiss, 2004). This means that people experience media as important also in dimensions of life that are considered less essential to them and that this way of asking questions about the media in daily life works as an instrument to measure perceived media reliance.

The first research question (see Introduction) was answered by way of descriptive statistics and mean values. In order to answer the second question - how perceived media reliance is structured along dimensions of daily human life - we ran a factor analysis on the sixteen variables. After creating three indexes based on the dimensions whose eigenvalues were above 1 (as indicated by the factor analysis), we ran Ordinary Least Squares Regression analyses to answer our third research question regarding the influence of demographic factors on the perceived media indispensability in daily life. The two following sections describe the results of these analytical procedures. 


\section{Results}

\section{Degrees of perceived media reliance}

By calculating the mean values of each item, we get an overview of perceived media reliance in daily human life (RQ1). Media are perceived as most important for gaining knowledge, followed by keeping in touch with others, and the desire to improve society (Table 2). Media are perceived as least important for love and sex life and for collecting things, underscoring that media are still considered indispensable mainly for communicative practices aimed at the larger world. It seems problematic to say that media penetrate deeply into the more mundane areas of daily life, as a majority of the mean values are below 4 and thus at the lower end of the scale, at least when considering dimensions of media reliance that the respondents are openly aware of.

Table 2: The importance of media for sixteen basic desires (means).

\begin{tabular}{llll}
\hline $\begin{array}{l}\text { How important do you find } \\
\text { media in order to... }\end{array}$ & Mean & $\begin{array}{l}\text { Standard } \\
\text { deviation }\end{array}$ & $\begin{array}{l}\text { Intrinsic motive } \\
\text { (after Reiss, 2004) }\end{array}$ \\
\hline ...gain knowledge & 5.6 & 1.3 & Curiosity \\
...keep in touch with others & 4.8 & 1.8 & Social contact \\
...improve society & 4.2 & 1.7 & Idealism \\
...make it on your own & 4.1 & 1.8 & Independence \\
...influence others & 3.7 & 1.7 & Power \\
...organize everyday life & 3.4 & 1.7 & Order \\
...enjoy food and drinks & 3.2 & 1.7 & Eating \\
...keep traditions alive & 3.1 & 1.7 & Honor \\
...take care of your family & 3.1 & 1.8 & Family \\
...get recognition from others & 2.9 & 1.6 & Acceptance \\
...stay in physical shape & 2.8 & 1.7 & Physical exercise \\
...have peace and quiet & 2.7 & 1.8 & Tranquility \\
...gain status & 2.7 & 1.5 & Status \\
...stay on par with others & 2.7 & 1.5 & Vengeance \\
...get love and sex & 2.5 & 1.7 & Romance \\
...collect things & 2.3 & 1.5 & Saving \\
\hline
\end{tabular}




\section{Three dimensions of perceived media reliance}

In order to answer our second question, we analyzed the underlying dimensions of perceived media reliance through a Principal Axis Factor analysis (Table 3). From the original sixteen variables, three dimensions with an eigenvalue above 1 emerged by way of the exploratory factor analysis, and subsequently they were summarized as indexes (all of which passed tests for internal reliability - Cronbach's alpha >.7). While figuring in this article as "dimensions of media reliance", we hypothesize the same three factors as "dimensions of mediatization" to be tested in our future longitudinal research.

Table 3: Factor analysis of media reliance in relation to fundamental dimensions of daily human life.

\begin{tabular}{|c|c|c|c|}
\hline $\begin{array}{l}\text { How important do you find media } \\
\text { in order to... }\end{array}$ & $\begin{array}{l}\text { (Re)productive } \\
\text { desires }\end{array}$ & $\begin{array}{l}\text { Recognition } \\
\text { desires }\end{array}$ & Civic desires \\
\hline ...take care of your family & .793 & .122 & .198 \\
\hline ...have peace and quiet & .758 & .141 & .091 \\
\hline ...stay in physical shape & .723 & .193 & .194 \\
\hline ...get love and sex & .719 & .296 & .076 \\
\hline ...enjoy food and drinks & .681 & .160 & .192 \\
\hline ...organize everyday life & .604 & .207 & .364 \\
\hline ...keep traditions alive & .578 & .312 & .207 \\
\hline ...collect things & .542 & .302 & .061 \\
\hline ...gain status & .295 & .774 & .173 \\
\hline ...stay on par with others & .276 & .761 & .176 \\
\hline ...get recognition from others & .347 & .642 & .215 \\
\hline ....influence others & .048 & .518 & .445 \\
\hline ...gain knowledge & .072 & .064 & .787 \\
\hline ...make it on your own & .448 & .169 & .530 \\
\hline ...improve society & .283 & .298 & .520 \\
\hline ...keep in touch with others & .165 & .285 & .457 \\
\hline Mean value for each dimension (Scale 1-7) & 2.88 & 3.02 & 4.66 \\
\hline
\end{tabular}

Comment: Principal axis factoring with Varimax rotation. Kaiser-Meyer-Olkin measure of sampling adequacy $=.928$. Loading scores above .45 have been set in bold. 
The first dimension describes perceived media reliance in relation to (re)productive desires. It captures the perceived importance of media for having peace and quiet, enjoying food and drinks, staying in shape, taking care of one's family, and so on. Here, the importance of media concerns the self, located in relation to the most intimate social group, or family, as well as the self as an autonomous human being (since the desire for independence, "make it on your own", also scores high in this factor). This dimension thus describes a practice-oriented realm of daily human life. However, while this dimension concerns fundamental matters of daily human life, media are experienced as less essential here than in the other two dimensions, as suggested by the mean value of the summarized index $(2.88$ on the scale 1-7).

The second dimension describes degrees of media reliance in relation to recognition desires. It concerns the importance of media in being recognized by others, asserting oneself in relation to others, gaining status from others, and influencing others. This dimension is, more than the first, marked by "other-directedness", or sensitivity to the preferences and expectations of others (Riesman, 1950/2001). As such, the dimension captures media reliance that concerns the self in an extended social group (of recognized others). The mean value of the index created from the variables making up this dimension is 3.02, which suggests that mediatization of this area of daily human life is experienced as more fundamental among the population than the previous dimension.

The third dimension captures perceived media reliance in relation to civic desires. The variables that make up this dimension relate to what it means to be a "good citizen" of society. They deal with the importance of media for the self-located in a wider social community (of largely unknown others); how people use media to gain knowledge, improve society, stay in touch with others, and maintain their independence. This dimension thus concerns the desire to be part of a larger community. Among the three factors identified in our analysis, this is where media are considered most important to people (mean value of index = 4.66). It is also the dimension that traditionally has gained the largest attention from media researchers, for instance, in the fields of journalism studies and political communication.

We see that there are strong connections between the three identified dimensions and aspects of media use and media experiences that have been discussed in previous research. Our findings support a rather classical understanding of media as a means of extending the social capacities of human beings, that is, broadening the scale of relating to others rather than for satisfying (re)production of a more practical nature. The three dimensions of mediatization illustrate what Berger and Luckmann (1966, p. 46) present as the difference between consociates (those we meet face-to-face) and contemporaries (of whom we have only more or less detailed 
recollections, or know merely by hearsay), a difference described as a continuum of different degrees of anonymity (p. 47; see also Schutz, 1967). In spite of new media (notably social media and various mobile apps) taking an ever-increasing presence in people's most intimate and (re)productive undertakings, as given by the notion of “deep mediatization” (Couldry and Hepp, 2016), media in general are still perceived as important above all for constructing a larger social world. It remains to see how this condition develops in the future. One prediction, based on our findings, would be to consider (re)production and recognition as 'yet-to-be-mediatized' dimensions of daily human life, while desires related to civic life are already inherently mediatized - at least if we judge from people's perceptions. This interpretation is not self-evident, however, as we will return to in the concluding part of the article.

\section{The demography of perceived media reliance}

Our final research question considers whether people in different demographic segments relate to the three dimensions of media reliance in different ways. In order to answer this question, we ran linear regression analyses on the three indexes (the dimensions of media reliance identified by the factor analysis in the previous section). We used age, gender, level of education, income, occupational status, and residential area as independent variables in the regression models (presented in Table 3). In what follows we discuss results that are statistically significant $(\mathrm{p}=<.05)$.

Turning to our first dimension - media reliance in relation to (re)productive desires - the results presented in Table 3 suggest that older people find media more important than younger people $\left(b=.017^{\star \star \star}\right.$ - meaning that the index-score increases, on average, by .017 steps every year). This corresponds with statistics on the amount of time that people in Sweden spend on media on average per day, where - if we exclude listening to music - older people (65-79 years) spend more time consuming media than younger generations (Nordicom, 2016). At the same time, however, the extent to which people use the internet and various online practices correlates negatively with age (Bergström, 2017). It is thus surprising that the increasingly connected lives of young people today do not translate into a higher estimation of perceived media reliance in this regard. As we will assert in the concluding discussion, however, this could strengthen the "disappearance of media" thesis formulated by Mark Deuze (2011, 2014). Additionally, in this dimension, men and people living in cities find media more indispensable than women and people in the countryside. Finally, the importance of media in relation to (re)production is more common in social segments at the lower end of the social hierarchy, as the index is negatively associated with education and income levels. 
Additionally, unemployed people find media more indispensable than people with white-collar occupations.

The experience of media as important for various forms of recognition desires - gaining status, influencing others, getting recognition, and staying on par with others - is more common in younger segments and urban environments, and less common among people with working class occupations (including the unemployed) and, perhaps surprising, people with relatively high incomes (SEK 30,000-49,999 per month). These results correspond to the usage patterns of social media and thus testify to the media-enhanced demographic bias of other-directedness as an orientation characterizing younger, non-working-class people in urban areas.

Lastly, finding media indispensable for exercising 'good' citizenship - what we call civic desires - increases with age. Also, women and urban dwellers, rather than men and people in the countryside find media to be important in this sense. The fact that this dimension of perceived media reliance comes out as the strongest one in our results may have something to do with the condition that news consumption is comparably widespread in the Nordic countries (Syvertsen, Mjøs, Enli, and Moe, 2014). We also know from previous research that news consumption is higher in the older segments of the Swedish population, and that the orientation towards more cosmopolitan types of media content (such as 'extra-local' news) is particularly prominent among women in metropolitan areas (Jansson and Lindell 2015; Lindell, 2015). This kind of media use is also regarded as being particularly valuable in the Nordic countries (Hagen, 1994; Bengtsson, 2012), and may therefore be particularly easy to put forward in the survey study by the respondents. It would have been highly relevant to also correlate the indexes with uses of different kinds of media. Such analyses would control for the role of different media specificities in mediatization processes. In this dataset, however, we lacked such questions, which is why the analysis of that dimension will have to wait until the study is replicated.

Our results suggest that the general experience of media as indispensable to daily human life is primarily an urban phenomenon. Various other demographic characteristics also play a role, especially when it comes to the importance of media in relation to (re)production, which is particularly pronounced in less privileged segments of society. While men find media relatively important for the latter, women feel more dependent on media in order to be 'good citizens'. Having said this, it must be noted that our models only explain a rather small share of the variation in the dimensions of media reliance (as indicated by the R-square measurements in Table 4). This implies that other factors are also important in order to explain synchronic differences in perceived media reliance as well as diachronic transformations, in other words mediatization, of daily human life. 
Table 4: Regression analysis (ordinary least square) - demographic variables related to the three dimensions of media reliance (B-coefficients).

\begin{tabular}{|c|c|c|c|}
\hline & \multicolumn{3}{|c|}{ Dimension of media reliance } \\
\hline & $\begin{array}{l}\text { (Re)productive } \\
\text { desires }\end{array}$ & $\begin{array}{l}\text { Recognition } \\
\text { desires }\end{array}$ & $\begin{array}{l}\text { Civic } \\
\text { desires }\end{array}$ \\
\hline Age (16-85) & $.017^{\star \star \star}$ & $-.007^{\star \star \star}$ & $.006^{\star \star \star}$ \\
\hline Woman (ref: man) & $-.174^{\star \star \star}$ & .041 & $.368^{\star \star \star}$ \\
\hline \multicolumn{4}{|l|}{ Level of education (ref: low) } \\
\hline High school degree & -.081 & -.077 & .017 \\
\hline Post high school studies & $-.282^{\star \star \star}$ & -.047 & .079 \\
\hline University degree & $-.389 \star \star \star$ & -.106 & .080 \\
\hline \multicolumn{4}{|c|}{ Income (SEK) (ref: $<10,000 /$ month) } \\
\hline $10,000-19,999 /$ month & $.219^{\star}$ & .080 & .107 \\
\hline $20,000-29,999 /$ month & -.059 & -.126 & -.074 \\
\hline 30,000-39,999/month & -.124 & $-.229^{\star}$ & -.090 \\
\hline $40,000-49,999 /$ month & -.182 & $-.237^{\star}$ & -.084 \\
\hline$>50,000 /$ month & -.166 & -.123 & -.107 \\
\hline \multicolumn{4}{|c|}{ Occupational status (ref: unemployed) } \\
\hline White-collar & $-.187^{\star}$ & -.066 & .005 \\
\hline Upper white-collar & -.116 & .081 & -.024 \\
\hline Worker & -.159 & $-.229 \star \star$ & -.113 \\
\hline Entrepreneur & -.191 & -.061 & -.091 \\
\hline \multicolumn{4}{|c|}{ Residential area (ref: rural area) } \\
\hline Big city centrally & $.338^{\star \star \star}$ & $.326^{\star \star \star}$ & $.225^{\star \star}$ \\
\hline Big city outskirts & $.283^{\star \star \star}$ & $.214^{\star \star \star}$ & $.161^{\star}$ \\
\hline City centrally & $.372^{\star \star \star}$ & $.336 * \star \star$ & $.197^{\star}$ \\
\hline City outskirts & .154 & .089 & .017 \\
\hline $10,000-30,000$ inhabitants & $.245^{\star \star}$ & $.199 *$ & .124 \\
\hline $200-10,000$ inhabitants & $.168^{\star}$ & .114 & .087 \\
\hline Constant & 2.365 & 3.419 & 4.094 \\
\hline $\mathbf{R}^{2}$ & $8.9 \%$ & $2.9 \%$ & $4.5 \%$ \\
\hline Adjusted $\mathbf{R}^{2}$ & 0.084 & 0.024 & 0.040 \\
\hline $\mathbf{N}$ & 3814 & 3814 & 3814 \\
\hline
\end{tabular}

Significance codes: ${ }^{\star} \mathrm{p}<.05 ;{ }^{* \star} \mathrm{p}<.01 ;{ }^{* * *} \mathrm{p}<.001$. 


\section{Concluding discussion: Perceived media reliance as a measure of mediatization}

The research instrument we have elaborated and tested in this paper, when used in a time series, would be capable of measuring perceived media reliance as one aspect of mediatization and, in turn, monitor this aspect of mediatization with regards to different dimensions of daily human life. To conclude this 'point zero' measurement, however, let us now return to the broader reflections on the limitations and wider implications of our results. First, it is an obvious limitation of our study that we do not have empirical data to control for actual media use among our respondents, and thus have not been able to grasp the role of media specificity in mediatization processes. This is something future research must look deeper into. Still, we can already see that our results are meaningful in light of research on media use. For instance, the importance of media in relation to recognition desires among younger people in urban areas as well as for civic desires among older groups, especially women in urban areas, corresponds with what we know about media uses in Sweden. Even though perceived media reliance seems to cut rather homogeneously across all social groups, the differences between social groups are in fact statistically significant.

Our findings concerning media reliance in relation to (re)productive desires distributed not only with regards to age but also negatively associated with education and income levels and salient among unemployed individuals rather than people with white-collar occupations - might also be related to previous work in media dependency theory. This strand of research suggests that individuals' media dependencies increase with raised levels of precariousness, including psychological, economic, or physical threats to individual well-being (Ball-Rokeach, 1985, p. 500). Similarly, while older people are over-represented among the audiences of traditional mass media, they often experience an ambiguous "sense of urgency" related to the practical need to adapt to new media forms in order to fulfill the desire for independence in their daily lives (Givskov, 2017). Such senses of urgency may explain why the elderly, who are less likely than the young to use digital media for the mundane practices of everyday life, more strongly perceive their impact in daily life.

This leads us to two alternative hypotheses concerning the mediatization of daily human life. On the one hand, as we stated earlier in the article, (re)productive desires and recognition desires might be hypothesized as 'yet-to-be mediatized' domains of daily human life. Such an argument would imply that current writings on "deep mediatization" should be read foremost as predictive, meaning that (re)production and recognition are the type of desires that will be foremost 
affected by mediatization in the near future due to the expansion of social media, mobile apps, etc.

As already mentioned, then, our results may, on the other hand, indicate that those respondents who perceive and express instances of media reliance in certain domains of their lives are in fact those who are 'media-independent' enough to see the presence of media in everyday life, that is, those whose lives are the least 'datafied'. If so, this could be a manifestation of the "disappearance of media” thesis, formulated by Deuze (2011, p. 137; 2014) and developed in the “deep mediatization" thesis by Couldry and Hepp (2016; see also Hepp, 2016). Couldry and Hepp argue that the current phase of all-pervasive mediatization coincides with digitalization and datafication and affects fundamental elements of all social processes that make up "reality". Such processes may explain why neither (re)production nor recognition are experienced as dimensions of daily life that are particularly reliant on media (even though they may be so from a more practical point of view), and why media are considered more important among groups that are not likely to be at the forefront of digitalization and datafication (older and less educated people). We need replications of the current study to assess which of the mediatization hypotheses (if any) is most valid.

This brings us to the second reflection. The above discussions indicate that there is a need to problematize the idea of "deep mediatization" (Couldry and Hepp, 2016), and particularly to broaden how it can be approached empirically. The 'depth', or intensity, of mediatization can be addressed, on the one hand, from the observation of media technologies saturating and establishing stronger amalgamations within expanding areas of everyday life (see also Andersen, 2018), and, on the other hand, from the phenomenological perspective of experiences of media indispensability in daily life. Couldry's and Hepp's thesis (2016) in general builds on the first alternative, yet they argue strongly for phenomenological approaches to people's experiences of mediatized lifeworlds (see also Hepp and Krotz, 2014). Our study is an attempt to explore such experiences but to also quantify them and as such make them measurable over time and across different social strata. While the technology-oriented approach to mediatization attains relevance when it comes to describing general tendencies concerning what mediatization looks like (for example, the emergence of permanently connected lives), it should, we argue, be complemented with studies that can also validate and assess over time to what extent different groups actually feel that these transformations affect their lives, which to a great deal is dependent on material, social and cultural factors external to media saturation per se (such as generational differences and social stratification).

This study represents a humble step in that direction. It provides a starting point for longitudinal research through future replications of the present 
study, which should be able to confirm whether the felt reliance on media will deepen and also spread to other realms of daily life - that is, affecting other basic desires - and to other social groups. If such strengthened experiences of media reliance were to be found, one could make a stronger case for the notion of mediatization in general and "deep mediatization" in particular.

In this connection, finally, we should also call attention to the fact that our study concerns one specific cultural context (Sweden). One might argue that this is a particularly apt context for undertaking a study of mediatization, considering the very high level of media penetration, especially in terms of digitalization. As discussed above, however, media saturation in general should not be taken as evidence of media reliance. Rather, such relationships must be further investigated. If we, in line with Krotz (2017), presuppose that "in every society, different paths of mediatization are possible” (p. 114) and acknowledge, in accordance with Ball-Rokeach (1985), that individual media dependency is ultimately determined by a "structural dependency" (p. 490) that varies with media system and other cultural-specific circumstances, cross-national comparative studies should be undertaken along with future time series. Future research should thus detail how actual patterns of media access and use correlate with experiences of media reliance in relation to basic dimensions of human life - both on the individual level, in particular social settings, and on the global scale.

\section{References}

Andersen, J. (2018). Archiving, ordering, and searching: Search engines, algorithms, databases, and deep mediatization. Media, Culture \& Society, 0163443718754652.

Aristotle (1953). The Nicomachean ethics (original work published 330 BCE). New York: Penguin.

Ball-Rokeach, S. J. (1985). The origins of individual media-system dependency: A sociological framework. Communication Research, 12(4), 485-510.

Barnes, J., Thompson, J. A. K., \& Tredennick, H. (1976). The ethics of Aristotle: The Nicomachean ethics. England: Penguin Books.

Berger, P. L., \& Luckmann, T. (1966). The social construction of reality. New York: Anchor Books.

Bergström, A. (2017). Digital Equality and the Uptake of Digital applications among seniors of different age. Nordicom Review, 38(1), 79-91.

Bengtsson, S. (2012). Imagined user modes: Media morality in everyday life. International Journal of Cultural Studies, 15(2), 181-196.

Bernard, L. C., Mills, M., Swenson, L., \& Walsch, R. P. (2005). An evolutionary theory of human motivation. Genetic, Social and General Psychology Monographs, 131(2), 129-184.

Bishop, J. (2007). Increasing participation in online communities: A framework of human-computer interaction. Computers in human behaviour, 23, 1881-1893.

Couldry, N. (2012). Media, society, world: Social theory and digital media practices. Cambridge: Polity Press. 
Couldry, N., \& Hepp, A. (2013). Conceptualizing mediatization: Contexts, traditions, arguments. Communication Theory, 13(3), 191-202.

Couldry, N., \& Hepp, A. (2016). The mediated construction of reality. Cambridge: Polity Press.

Deacon, D., \& Stanyer, J. (2015). 'Mediatization and' or 'mediatization of? A response to Hepp et al. Media, Culture \& Society, 37(4), 655-657.

Deci, E. L., \& Ryan, R. M. (1985). Intrinsic motivation and self-determination in human behaviour. New York: Plenum.

Descartes, R. (1958). The passion of the soul (original work published 1637). New York: Modern Library.

Deuze, M. (2011). Media life. Media, Culture \& Society, 33(1), 137-148.

Deuze, M. (2014). Media life and the mediatization of the lifeworld. In A. Hepp \& F. Krotz (Eds.), Mediatized worlds: Culture and society in a media age. London: Palgrave.

Givskov, C. (2017). Growing old with mediatization. Nordicom Review, 38(1), 53-64.

Hagen, I. (1994). The ambivalences of TV news viewing: Between ideals and everyday practices. European Journal of Communication, 9(2), 193-220.

Harris, M. (1976). History and significance of the emic/etic distinction. Annual review of Anthropology, 5, 329-350.

Hasebrink, U., \& Popp, J. (2006). Media repertoires as a result of selective media use. A conceptual approach to the analysis of patterns of exposure. Communications, 31(3), 369-387.

Hepp, A. (2016). Pioneer communities: Collective actors in deep mediatization. Media, Culture \& Society, 38(6), 918-933.

Hepp, A., Hjarvard, S., \& Lundby, K. (2015). Mediatization: Theorizing the interplay between media, culture and society. Media, Culture \& Society, 37(2), 314-324.

Hepp, A., \& Krotz, F. (2014). Mediatized worlds: Understanding everyday mediatization. In A. Hepp \& F. Krotz (Eds.), Mediatized worlds: Culture and society in a media age. London: Palgrave.

Hjarvard, S. (2013). The mediatization of culture and society. London: Routledge.

Hjarvard, S. (2019). As duas faces da conectividade digital: a transformação das dependências sociais [The Janus face of digital connectivity: The transformation of social dependencies]. In J. Ferreira, A. P. da Rosa, A. F. Neto, J. L. Braga \& P. G. Gomes (Eds.), Entre o que se diz e o que se pensa: onde está a midiatização? Santa Maria, Brazil: FACOS - Federal University of Santa Maria.

Jansson, A. (2014). Indispensable things: On mediatization, materiality, and space. In. K. Lundby (Ed.), Mediatization of communication: Handbooks of communication science (Vol. 21, pp. 273-296). Berlin: Mouton de Gruyter.

Jansson, A. (2018). Mediatization and Mobile Lives: A Critical Approach. London: Routledge.

Jansson, A., \& Lindell, J. (2015). News media consumption in the transmedia age: Amalgamations, orientations and geo-social structuration. Journalism Studies, 16(1), 79-96.

Katz, E., Blumler, J. G., \& Gurevitch, M. (1973). Uses and gratifications research. The Public Opinion Quarterly, 37(4), 509-523.

Knoblauch, H. (2013). Communicative constructivism and mediatization. Communication Theory, 23, 297-315.

Krasnova, H., Spiekermann, S., Koroleva, K., \& Hildebrand, T. (2010). Online social networks: Why we disclose. Journal of Information Technology, 25(2), 109-125.

Krotz, F. (2007). The meta-process of 'mediatization' as a conceptual frame. Global Media and Communication, 3(3), 256-260. 
Krotz, F. (2014). Mediatization as a mover in modernity: Social and cultural change in the context of media change. In K. Lundby (Ed.), Mediatization of communication (Handbook of communication sciences, vol. 22). Berlin: De Gruyter Mouton.

Krotz, F. (2017). Explaining the mediatization approach. Javnost - The Public, 24(2), 103-118.

Lindell, J. (2014). Cosmopolitanism in a mediatized world: The social stratification of global orientations (Doctoral dissertation, Karlstads universitet). Karlstad: Karlstad University Studies.

Lundby, K. (2014). Mediatization of communication. In K. Lundby (Ed.), Mediatization of communication (Handbook of communication sciences, vol. 22). Berlin: De Gruyter Mouton.

Lunt, P., \& Livingstone, S. (2016). Is 'mediatization' the new paradigm for our field? A commentary on Deacon and Stanyer $(2014,2015)$ and Hepp, Hjarvard and Lundby $(2015)$. Media, Culture \& Society, 38(3), 462-470.

Maslow, A. H. (1943). A theory of human motivation. Psychological Review, 50, 370-396.

Morley, D. (2009). For a materialist, non-media-centric media studies. Television \& New Media, 10(1), 114-116.

Nordicom (2016). Användningstid för olika medier i hela befolkningen 9-79 år en genomsnittlig dag 2016 (minuter) [Usage time for different media in the entire population between 9 and 79 years of age on an average day 2016 (in minutes)]. Retrieved October 29, 2017 from: http://www.nordicom.gu.se/sv/statistik-fakta/mediestatistik.

Peil, C., \& Röser, J. (2014). The meaning of home in the context of digitization, mobilization and mediatization. In A. Hepp \& F. Krotz (Eds.), Mediatized worlds: Culture and society in a media age. London: Palgrave.

Pittman, T. S., \& Ziegler, K. R. (2007). Basic human needs. Social psychology: Handbook of basic principles, 2, 473-489.

Reiss, S. (2004). Multifaceted nature of intrinsic human motivation: The theory of 16 basic desires. Review of General Psychology, 8(3), 179-193.

Reiss, S., \& Havercamp, S. M. (1998). Toward a comprehensive assessment of fundamental motivation: Factor structure of the Reiss profile. Psychological Assessment, 10, 97-106.

Riesman, D. (1950/2001). The lonely crowd. New Haven: Yale University Press.

Ryan, R. M., \& Deci, E. L. (2000). Intrinsic and extrinsic motivation: Classic definition and new directions. Contemporary Educational Psychology, 25, 54-67.

Schrøder, K. C. (2015). News media old and new: Fluctuating audiences, news repertoires and locations of consumption. Journalism Studies, 16(1), 60-78.

Schulz, W. (2004). Reconstructing mediatization as an analytical concept. European Journal of Communication, 19(1), 87-101.

Schutz, A. (1967). The phenomenology of the social world. Northwestern University Press.

Schwarz, S. H. (1994). Are there universal aspects in the structure and contents of human values? Journal of Social Issues, 50, 19-45.

Strömbäck, J. (2011). Mediatization and perceptions of the media's political influence. Journalism Studies, 12(4), 423-439.

Strömbäck, J., \& Dimitrova, D. V. (2011). Mediatization and media interventionism: A comparative analysis of Sweden and the United States. The International Journal of Press/ Politics, 16(1), 30-49.

Syvertsen, T., Mjøs, o. J., Enli, G. S., \& Moe, H. (2014). The media welfare state: Nordic media in the digital era. University of Michigan Press.

Vassileva, J. (2012). Motivating participation in social computing applications: A user modeling perspective. User Modeling and User-Adapted Interaction, 22,177-201. 